Research Article

\title{
Structure Strengthening Method for Enhancing Seismic Behavior of Soft Tunnel Portal Section
}

\author{
Guangyao Cui $(\mathbb{D})$ and Jianfei Ma $(\mathbb{C}$ \\ School of Civil Engineering, North China University of Technology, Beijing 100144, China \\ Correspondence should be addressed to Jianfei Ma; majfncut@163.com
}

Received 22 November 2020; Revised 3 January 2021; Accepted 19 January 2021; Published 31 January 2021

Academic Editor: Qian Zhang

Copyright (c) 2021 Guangyao Cui and Jianfei Ma. This is an open access article distributed under the Creative Commons Attribution License, which permits unrestricted use, distribution, and reproduction in any medium, provided the original work is properly cited.

\begin{abstract}
Tunnel portal sections always suffer serious damage under strong earthquakes. This paper aims to study the seismic performance of lining strengthening method in soft rock portal section by employing the model test. Firstly, the shaking table test considering the test cases, the modified input motions, the boundary condition, and monitoring equipment are conducted to simulate the seismic response of the soft tunnel portal section. Then, the lining strengthening method of increasing concrete grade is applied to the tunnel structure to study the aseismic performance of the soft rock tunnel portal section, and the seismic effects of the tunnel linings with different concrete grades are compared and analyzed. The result shows that the proportion of soft rock to total surrounding rock is the key factor affecting the seismic response of soft rock tunnel portal section; the larger the proportion of soft rock in surrounding rock, the more vulnerable the structure to earthquake damage; the seismic performance of the lining strengthening in hard rock portal is remarkable while limited in soft rock portal section. The stiffness and strength of the lining are larger than those of surrounding rock; the seismic performance of the soft portal section could hardly be improved only by the lining strengthening method. It is suggested to adopt both the structure strengthening and isolation method in the seismic design of soft portal section.
\end{abstract}

\section{Introduction}

Traditionally, underground structures were believed to suffer less damage during the strong earthquake since they were surrounded by rock or soil $[1,2]$. However, severe damage of the mountain tunnels was found in recent earthquake events [3-6]. Tunnel is an important component of traffic network; even slight earthquake damage may lead to traffic network paralysis and cause huge property loss [7]. Therefore, it is of great significance to study seismic response and aseismic measures of the mountain tunnels.

Scholars have done a lot of related investigations on the tunnel damage after several major earthquakes, which has provided the rich scientific support for the research of tunnel seismic design. The seismic damage of tunnel is mainly caused by the displacement difference between lining and surrounding rock under the action of seismic force [8]. The detailed investigation and database of tunnel seismic damage show that the fault zone, tunnel portal section, and the junction of soft and hard rock are the weak parts of the mountain tunnel in the earthquake. According to the lithology of surrounding rock, the tunnel portal section can be divided into the hard rock portal section and the soft rock portal section. In the 2008 Wenchuan earthquake, seven hard rock portal sections (Zaojiaowan, Maojiawan, quanquanquanguan, Futangguan, Taoguan, Caopo, and Dancanliangzi Tunnels) in Duwen section of G213 line were basically free from seismic damage, while three soft rock portal sections (Baiyunding, Youyi, and Ma'anshi Tunnels) along the same line suffered severe earthquake damage, such as lining cracking, spalling, block falling, staggering, and even collapse [9], as shown in Figure 1. Therefore, much attention has been paid to studying the seismic performance and the aseismic measures of the tunnel portal section. The isolation and strengthening are two main seismic methods for tunnel 


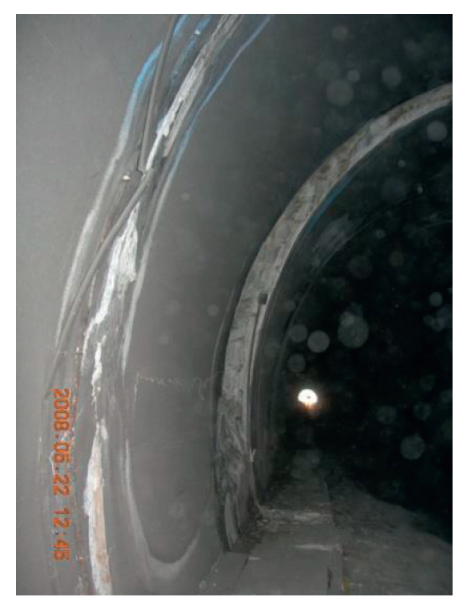

(a)

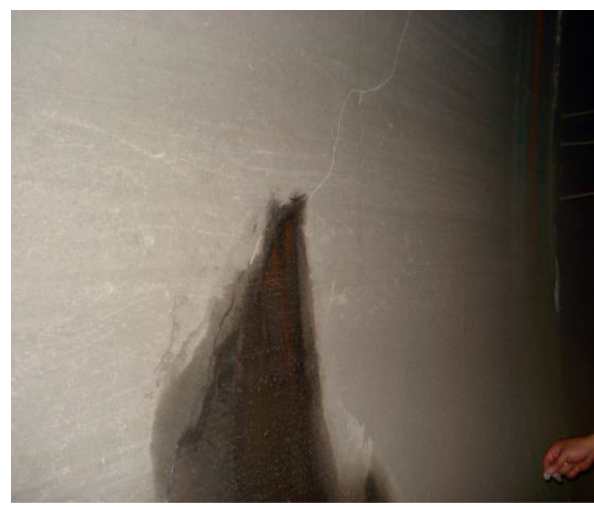

(c)

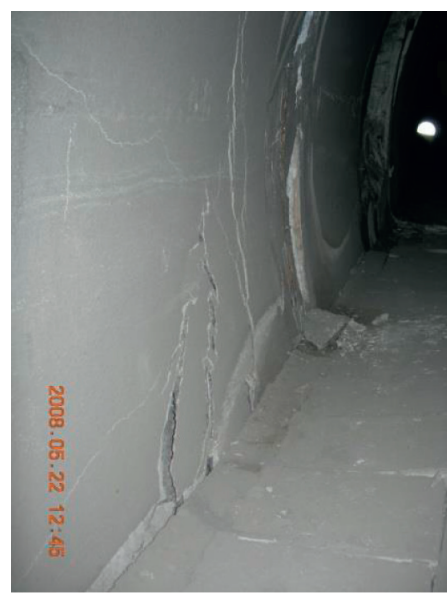

(b)

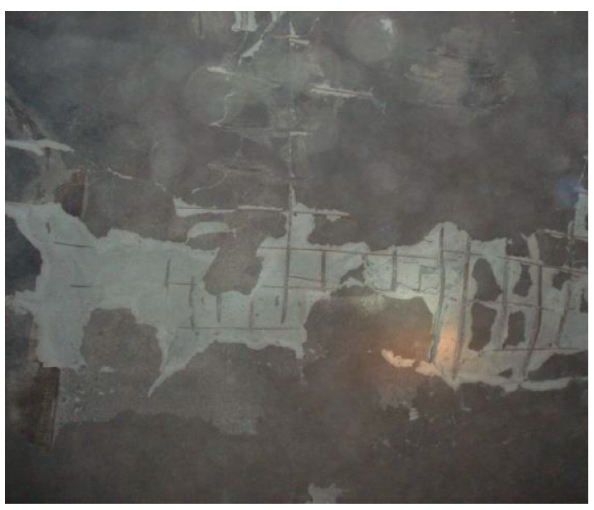

(d)

Figure 1: Seismic damage of soft rock tunnel portal in Wencchuan Earthquake. (a) Staggered lining in Baiyunding Tunnel. (b) Lining cracking of Baiyunding Tunnel. (c) Inclined cracking and water seepage of lining in Ma'anshi Tunnel. (d) Lining spalling and block dropping in Youyi Tunnel.

engineering [10]. Generally, the isolation layer is the most simple and effective method; that is, a layer of flexible material is employed between the rock and linings to minimize the seismic motion from the linings $[11,12]$. The application of the isolation layer changes the rock-lining system into the rock-layer-lining system [13]. The layer could decrease the seismic displacement and the internal force of linings, so as to improve the seismic performance of the tunnel structures [14]. Previous studies have proved that the seismic effect of the isolation layer in the hard rock is remarkable while limited in the soft rock tunnel. However, due to the construction difficulty and the high construction cost, the damping layer is only used in the test section of the tunnel and has not been widely used in the tunnel seismic design. Another isolation method is that the damping joint with the simple construction technology can achieve almost the same effect of shock absorption, while the existence of the joint may reduce the waterproof performance of tunnel so as to shorten service life of the tunnel [15]. And, the strengthening method was proposed to enhance the seismic performance by increasing the mechanical properties of the rock and linings [16]. The rock strengthening method such as grouting and rock bolt can improve the bearing capacity of surrounding rock by reinforcing, so as to avoid tunnel disaster caused by rock instability in earthquake $[17,18]$. The rock reinforcement plays a significant role in enhancing seismic behavior of the soft rock tunnel causing the properties difference between the linings and surrounding rock. Rapid development in concrete has enabled what is known as the fiber reinforced concrete (FRC), that is, adding some very small fibers to replace the convention steel bar inside the concrete [10]. In the seismic active region, the seismic performance and structure vulnerability of tunnel are of great concern; the use of fiber reinforced concrete (including steel, polypropylene, glass, carbon, etc.) could increase the seismic performance of the tunnel [19]. As the seismic performance of fiber reinforced concrete lining is affected by fiber type, length, volume content, and construction technology, only steel fiber concrete has been used in tunnel engineering on a large scale [20]. Among the numerous lining reinforcement methods, it is the simplest and most effective method to improve the mechanical properties of concrete by changing the strength of cement and the proportion of cement, sand, stone, and water. According to the relevant Chinese code, there are 14 grades of concrete from low to high, from C12 to C80 [21]. The greater the number is, the greater the strength and stiffness of concrete is. In addition, 
the method of improving concrete grade will not face the problems of complex construction technology and high engineering cost, which has made it the most widely used seismic technology in tunnel engineering.

Shaking table test provides an effective method for real ground motion excitation of tunnel structure, and its cost is lower than that of prototype test. By adopting the similar materials, the seismic wave of earthquake events, and the shaking table, the shaking table test could simulate the true reaction of tunnel during the earthquake [7]. Nowadays, research of the shaking table test mainly concentrates on the tunnel portal, seismic method of tunnel portal, tunnel crossing the fault, and tunnel portal under biased pressure. However, there are few shaking table tests on seismic response and structure strengthening of tunnel portal section, especially in soft soil. This paper aims to study the seismic response of the structure strengthening of the portal section of the soft portal. Firstly, a large shaking table test considering the modify waves, similar materials, shaking table test, and monitoring system are conducted to study the seismic response of the soft portal section. Afterwards, the structure strengthening method by increasing concrete grade is employed in test to investigate the its seismic effect. Finally, scientific suggestions are put forward for seismic design of portal section in soft rock. This study is of great significance to improve the seismic performance of tunnel soft rock portal section.

\section{Shaking Table Test}

2.1. Engineering Prototype. Baiyunding Tunnel is located in G213 national highway (Dunying Road), Wenchuan County, Aba Tibetan and Qiang Autonomous Prefecture, Sichuan Province, China, with an altitude of $1044 \mathrm{~m}$. The depth of the tunnel portal is $14-30 \mathrm{~m}$, and the overburden layer of the mountain slope at the entrance is quaternary colluvium and diluvium, which are mainly composed of silty clay and mudstone, with the rock grade of $\mathrm{V}$ [22]. The bedrock under the overburden is mainly composed of sandstone and limestone, with the rock grade of II. The height and span of tunnel cross-section is 9.66 and $11.34 \mathrm{~m}$, respectively. The primary support is C25 shotcrete with a thickness of $18 \mathrm{~cm}$, and the secondary lining is C25 reinforced concrete with a thickness of $55 \mathrm{~cm}$, as shown in Figure 2.

2.2. Test Cases. Table 1 lists the cases of the scaled shaking table test, and four commonly used concrete grades (i.e., C25, C30, C35, and C40) are adopted to study the seismic response of tunnel and investigate the aseismic behavior of the lining strengthening method, as shown in Figure 3.

2.3. Shaking Table and Test Box. The test was carried out by using a three-dimensional, six-degree-of-freedom large shaking table and model test box owned by China Nuclear Power Research and Design Institute, as shown in Figure 4. The length and width of the large shaking table are both $6 \mathrm{~m}$, and its maximum load is $60 \mathrm{t}$. The frequency of the table is

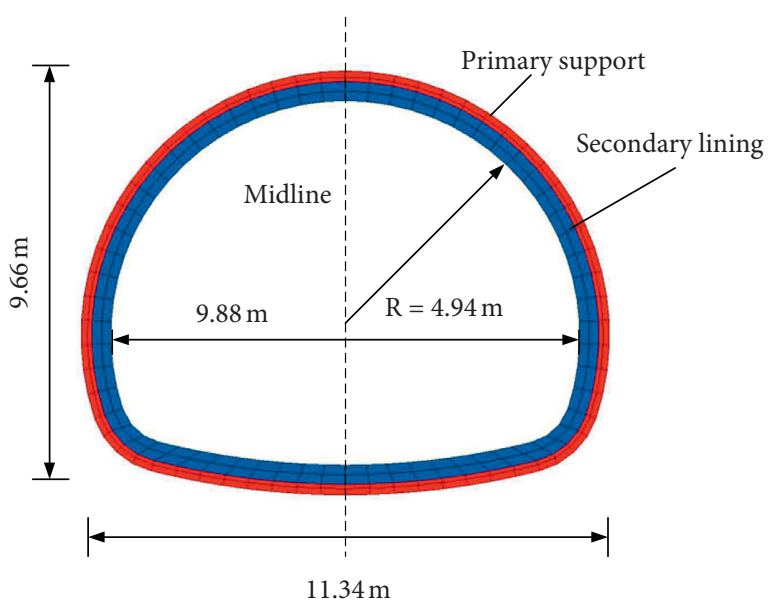

Figure 2: Tunnel section.

TABle 1: Test cases.

\begin{tabular}{lcccc}
\hline $\begin{array}{l}\text { Test } \\
\text { case }\end{array}$ & $\begin{array}{c}\text { Concrete } \\
\text { grade }\end{array}$ & $\begin{array}{c}E_{\mathrm{c}} \\
\left(\times 10^{4} \mathrm{~N} / \mathrm{mm}^{2}\right)\end{array}$ & $\begin{array}{c}f_{\mathrm{t}} \\
\left(\mathrm{N} / \mathrm{mm}^{2}\right)\end{array}$ & $f_{\mathrm{c}}\left(\mathrm{N} / \mathrm{mm}^{2}\right)$ \\
\hline 1 & C25 & 28 & 1.27 & 11.9 \\
2 & C30 & 30 & 1.43 & 14.3 \\
3 & C35 & 31.5 & 1.57 & 16.7 \\
4 & C40 & 32.5 & 1.71 & 19.1 \\
\hline
\end{tabular}

${ }^{*} E_{\mathrm{c}}$ is the elastic modulus, $f_{\mathrm{t}}$ is the axial tensile strength, and $f_{\mathrm{c}}$ is the axial compressive strength.

$0.1-100 \mathrm{~Hz}$, and the maximum displacements in three directions are all $150 \mathrm{~mm}$. Under the full load condition, the maximum horizontal and vertical accelerations are $1 \mathrm{~g}$ and $0.8 \mathrm{~g}$, respectively. The model box (see Figure 5) is $2.5 \mathrm{~m}$ long, $2.5 \mathrm{~m}$ wide, and $2 \mathrm{~m}$ high. In order to absorb the energy of reflected wave and reduce the friction resistant between the soil and outer walls, the molded polystyrene film foam board with PVC film (see Figure 6) is pasted on the inner side of box. In addition, a layer of gravel (see Figure 7) is cemented at the box bottom to reduce the relative sliding between box base and soil.

2.4. Similarity Ratio and Similar Materials. According to the similarity theory, and considering the bearing capacity of the shaking table, the geometric similarity ratio of this test is set as 30 . The similarity ratio of elastic modulus is chosen as 45 , and similarity ratio of acceleration is chosen as 1 . Table 2 lists similarity ratios of other major parameters.

After many times of laboratory mechanical tests (Figure 8), combined with the existing literature, river sand, barite powder, fly ash, coarse quartz sand, fine quartz sand, rosin, petroleum jelly, and waste engine oil of train are selected to simulate surrounding rock. Lining structure is simulated with gypsum admixture, and the plaster-water ratios of C25, C30, C35, and C40 secondary lining structure are $1.48,1.56,1.67$, and 1.76 , respectively. Some steps of lining fabrication are shown in Figure 9. 


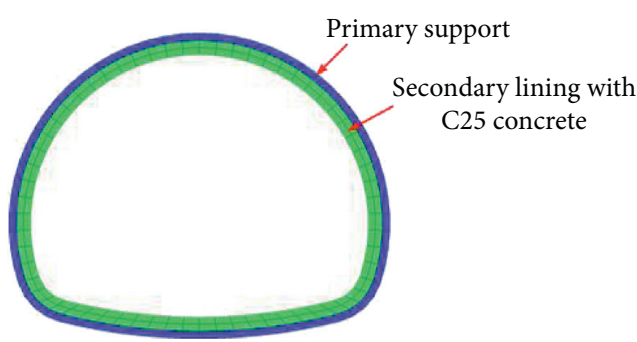

(a)

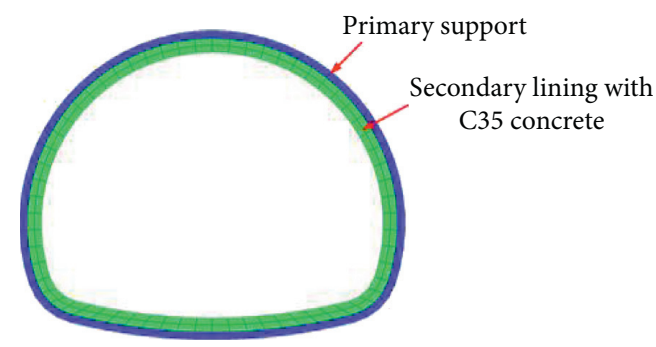

(c)

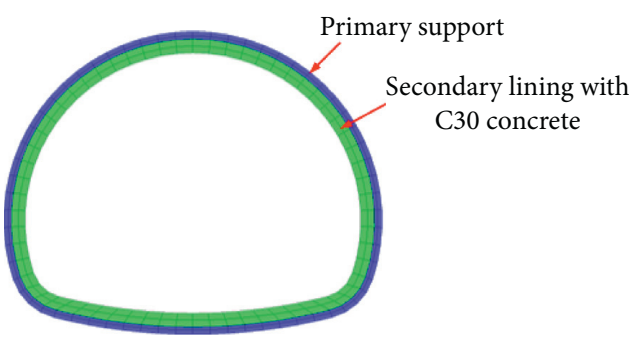

(b)

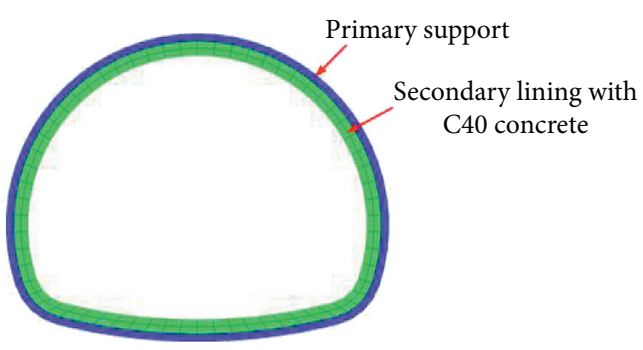

(d)

Figure 3: Tunnel cases. (a) case 1; (b) case 2; (c) case 3; (d) case 4.

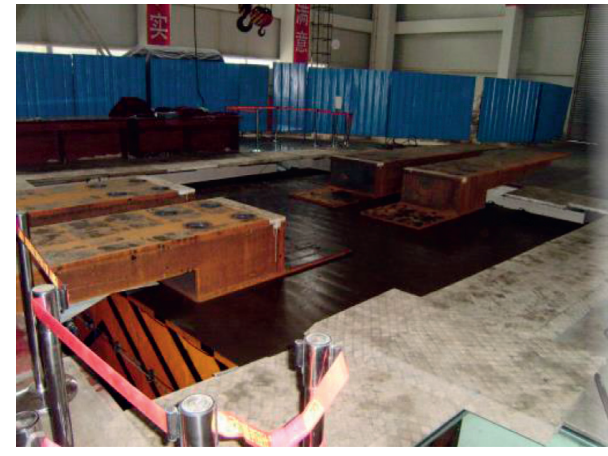

Figure 4: Shaking table.

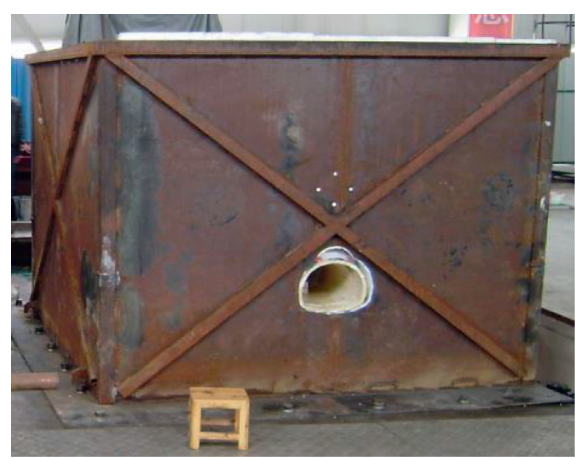

Figure 5: Model test box.

2.5. Test Apparatus and Monitoring System. The statistics collected system is composed of dynamic strain acquisition and dynamic strain/ICP data conversion sensor, as shown in Figure 10. The acceleration, strain, and contact stress of tunnel supporting structure are collected in the test, and the apparatuses used for recording these parameters are

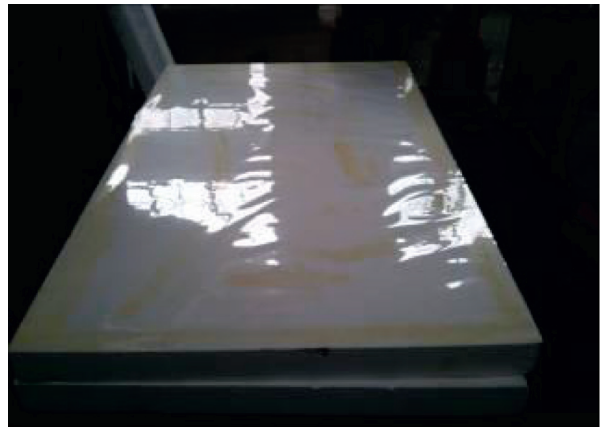

FIGURE 6: Polystyrene film foam board with PVC film.

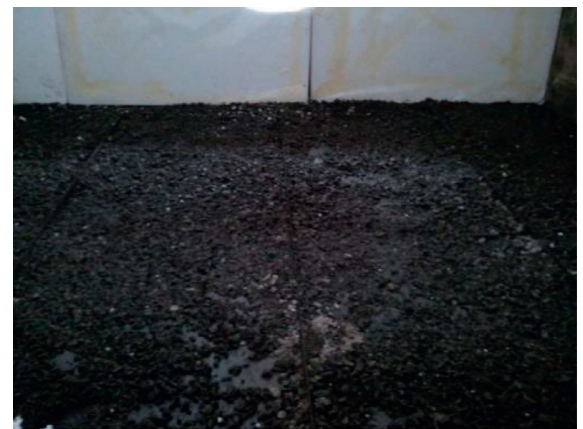

Figure 7: Gravel cemented at box bottom.

TST1010L unidirectional accelerometer, TST1010LS threeway accelerometer, BE120-5AA resistance strain gauge, and DYB-1 microearth stress sensor, as is shown in Figure 11.

Figure 12 shows the layout of monitoring sections in this paper. Monitoring sections $\mathrm{A}$ and $\mathrm{E}$ are set in the soft section and the hard rock sections, respectively. Sections B, C, and D are set at the junction of soft and hard surrounding rock, and the positions where the sections $\mathrm{B}, \mathrm{C}$, and $\mathrm{D}$ intersect the 
TABLE 2: Similarity ratio of major parameters.

\begin{tabular}{lc}
\hline Parameter & Similarity ratio \\
\hline Frequency & 0.18 \\
Stain & 1 \\
Young's modulus & 1 \\
Internal friction angle & 1 \\
Angular displacement & 1 \\
Density & 1.5 \\
Mass & 40500 \\
Time & 5.477 \\
Velocity & 5.477 \\
Linear displacement & 30 \\
Stress & 45 \\
Stiffness & 1350 \\
Damping & 7394 \\
Moment & 121500 \\
\hline
\end{tabular}

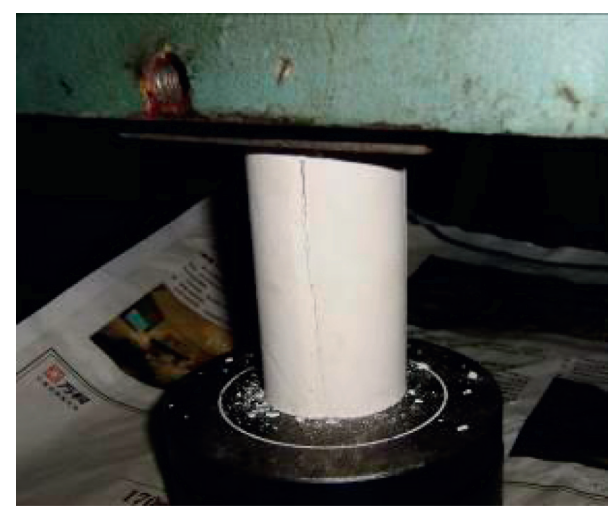

Figure 8: Laboratory mechanical test.

interface of soft and hard rock are inverted arch, side wall, and vault, respectively. In general, the range of soft rock in cross-section gradually decreases from section A to section E.

The layout of the test sensors in each monitoring section is shown in the Figure 13. Microearth stress box (T) and longitudinal strain gauge (ZY) are set on the outside the vault, and one-way accelerometer ( $\mathrm{J}$ ) is set inside of the inverted arch. In the meantime, the transverse strain gauges (Y) are arranged in pairs on the inside of the vault, side wall, and inverted arch.

2.6. Dynamic Motion and Loading Process. The dynamic motion used in test is the seismic acceleration waves recorded at the Wolong Station in Wenchuan Earthquake on May 12, 2008, which is with a duration of $164.0 \mathrm{~s}$ and recording interval of $0.005 \mathrm{~s}$. After amplitude modulation, similar transformation, filtering and base correction, the acceleration time history of 7-Ms test loading wave is shown in Figure 14.

The predominant frequencies of waves in east-west, north-south, and vertical directions are $16 \mathrm{~Hz}, 17 \mathrm{~Hz}$, and $21 \mathrm{~Hz}$, respectively. According to the modal analysis, the predominant frequencies of the test box and the tunnelsurrounding rock system are $49.71 \mathrm{~Hz}$ and $5.57 \mathrm{~Hz}$, respectively. In short, the predominant frequencies of the test loading wave, test box, and tunnel-surrounding rock system are quite different, and resonance phenomenon will not occur, which meets the dynamic test requirements. The model test is loaded in two steps. Firstly, input the white noise wave with small amplitude to check the working state of data acquisition system. Then, input the dynamic motion and collect the test data (i.e., acceleration, strain, and contact stress). During the excitation, the east-west, northsouth, and vertical directions of seismic waves correspond to the longitudinal, transverse, and vertical directions of tunnel.

2.7. Safety Factor. Although the shaking table test can accurately simulate the dynamic response of tunnel in earthquake, due to the limitation of monitoring equipment, it can only analyze the deformation, stress, and strain of the structure, and cannot directly obtain the internal such as the axial force and bending moment of the structure. In view of this, the calculation of axial force and bending moment of lining structure (Figure 15) are derived as equation (1).where $N$ is the axis force, $M$ is the bending moment, $E$ is elastic modulus, $\sigma_{1}$ is internal stress of lining, which is calculated by equation (2), and $\sigma_{2}$ is external stress of lining, which is calculated by equation (2).

$$
\begin{aligned}
& N=\frac{E\left(\sigma_{1}+\sigma_{2}\right) b h}{2}, \\
& M=\frac{E\left(\sigma_{1}+\sigma_{2}\right) b h^{2}}{2}, \\
& \sigma_{1}=\zeta\left(\sigma_{n 1}+\sigma_{n 2}\right)+\frac{\zeta\left(\sigma_{n 1}+\sigma_{n 2}\right)}{\xi}, \\
& \sigma_{2}=\zeta\left(\sigma_{n 1}+\sigma_{n 2}\right)+\frac{\zeta\left(\sigma_{n 1}+\sigma_{n 2}\right)}{\xi},
\end{aligned}
$$

where $\zeta$ is the reciprocal of lining zone layers; $\sigma_{n 1}$ is the normal stress of the internal grid; $\sigma_{n 2}$ is the normal stress of the external zone; and $\sigma_{n 1} / \sigma_{n 2}$ is derived by equation (3).

$$
\sigma_{n}=\sigma_{x} \cos ^{2}(-\alpha)+\sigma_{y} \sin ^{2}(-\alpha)+\sigma_{x y} \sin (-2 \alpha),
$$

where $\alpha$ is the angle between the line of centroid of inner and outer elements and vertical direction, which is calculated by equation (4) and $\left(x_{1}, y_{1}\right)$ and $\left(x_{2}, y_{2}\right)$ are the centroid coordinates of the inner and outer zones, respectively.

$$
\alpha=\arctan \left(\frac{x_{2}-x_{1}}{y_{2}-y_{1}}\right) \text {. }
$$

In this paper, we use the safety factor from the Code for Design of Railway Tunnel to estimate the stability and the safety of the tunnel [23], which is calculated by equation (5). The larger the safety factor, the safer the structure.

$$
\begin{aligned}
& K N \leq \varphi \delta R_{a} b h, \\
& K N \leq \varphi \frac{1.75 R_{l} b h}{\left(6 e_{0} / h\right)-1},
\end{aligned}
$$




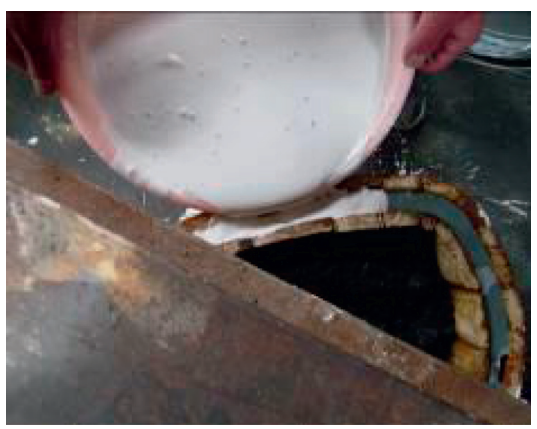

(a)

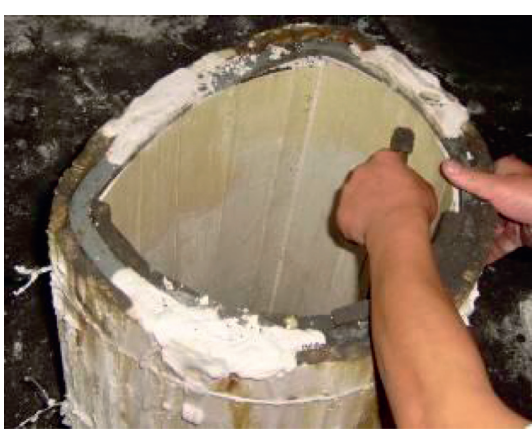

(b)

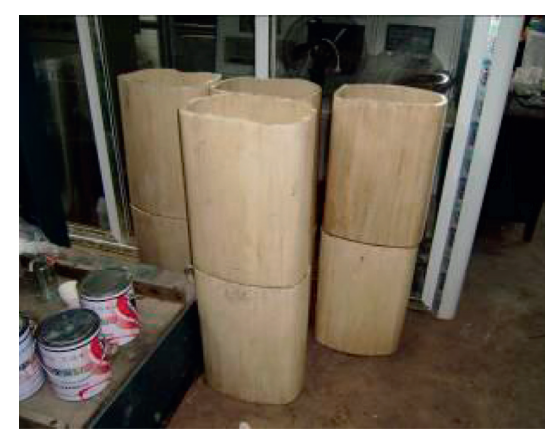

(c)

FIGURE 9: Lining fabrication. (a) Lining pouring. (b) Removing the mold. (c) Lining drying.

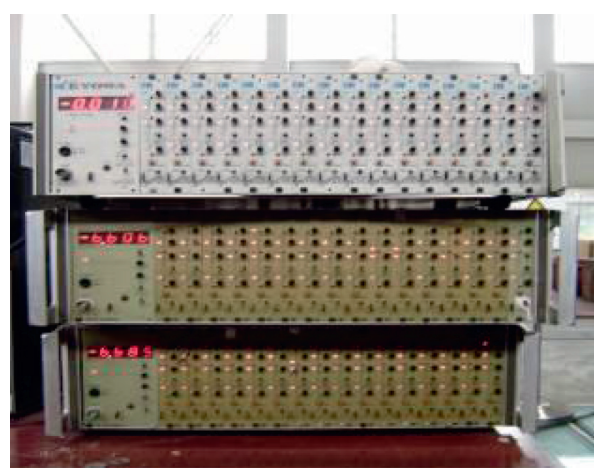

(a)

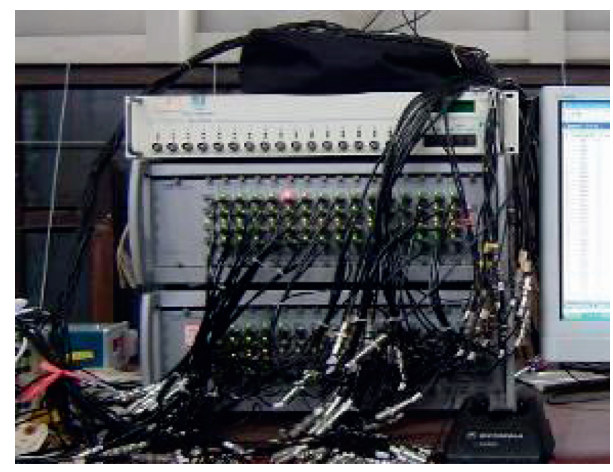

(b)

Figure 10: Statistics collected system. (a) Dynamic strain acquisition. (b) Dynamic strain/ICP data conversion sensor.

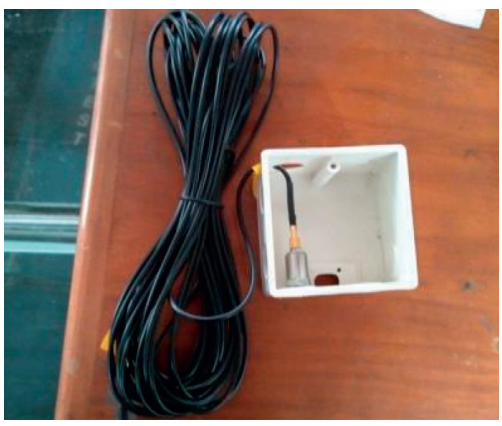

(a)

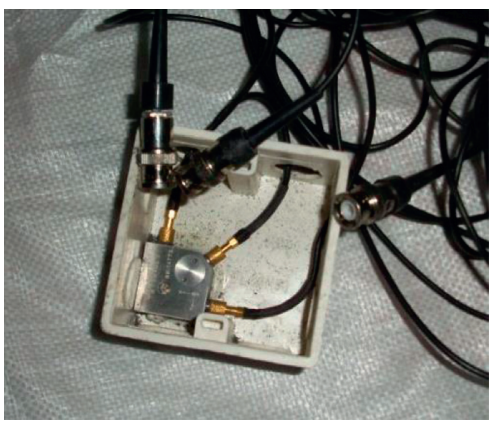

(b)

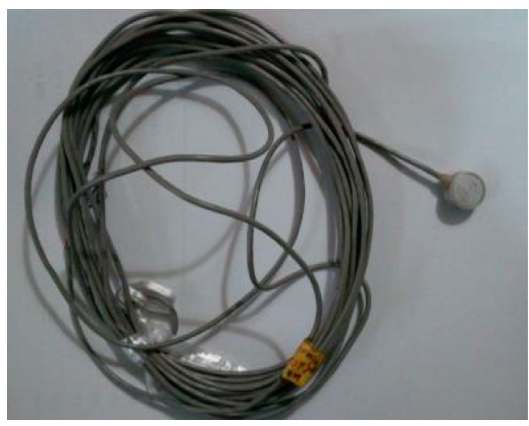

(c)

Figure 11: Monitoring sensor. (a) Unidirectional accelerometer. (b) Three-way accelerometer. (c) Microearth stress sensor.

where $K$ is safety factor; $\varphi$ is longitudinal bending coefficient; $\delta$ is influence coefficient of axial force eccentricity; $R_{a}$ is ultimate compressive strength of concrete; $b$ is width of tunnel section; $h$ is thickness of section; and $R_{l}$ is ultimate tensile strength of concrete.

\section{Results and Analysis}

3.1. PGA Amplification Factor. The acceleration time history curve of tunnel vault is plotted in Figure 16 (taking section A of case 3 as an example). Figure 17 shows the acceleration time history of the bottom of the box. Peak ground acceleration (PGA) of monitoring sections (i.e., A, B, C, D, and E) is extracted from acceleration time-history curves, and the PAG of the box bottom is $92 \mathrm{gal}$.

Figure 18 shows the variation of PGA with monitoring sections. Overall, a negative relationship was observed between the PGA and range of soft rock in the earthquake. The PGA of the hard rock section (E) is small, increases gradually from section $\mathrm{D}$ to $\mathrm{B}$ at the junction of hard and soft rock, and finally reaches the maximum value at the soft rock section (A). The larger the proportion of soft rock in the tunnel- 


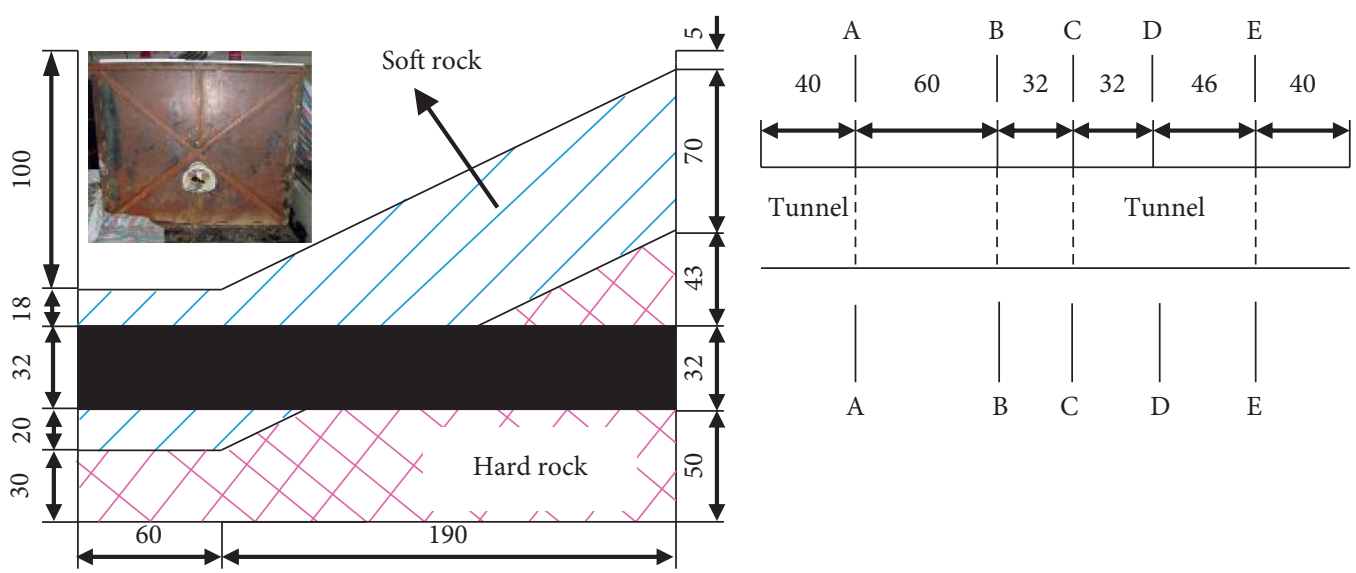

(a)

(b)

Figure 12: Monitoring sections. (a) Sectional view. (b) Top view (unit: $\mathrm{cm}$ ).

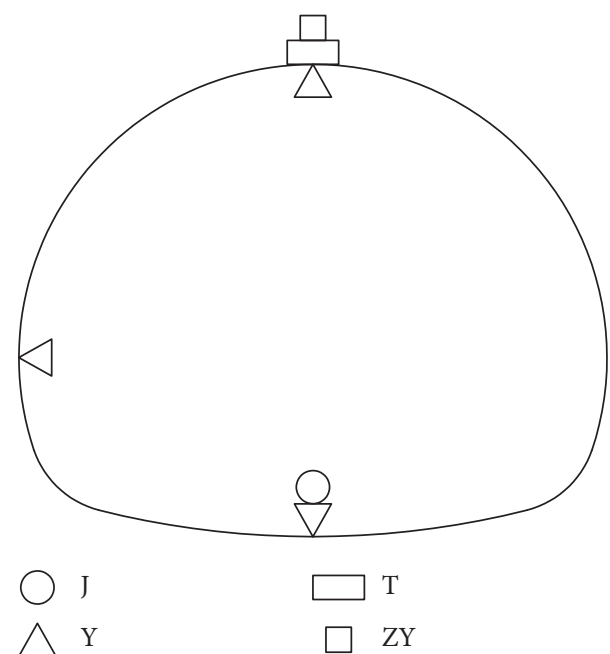

FIGURE 13: Layout of monitoring sensors.

surrounding rock section, the greater the PGA. This is one of the reasons why soft rock tunnels often suffer from severe earthquake damage. Table 3 lists the PAG amplification factor of test, that is, the percentage increase in PGA at the tunnel vault relative to the PGA at the bottom of the test box. When the concrete grade is changed from C25 to C40, the PGA of hard rock section (E) is basically unchanged. However, for the hard and soft rock junction (i.e., sections D, $\mathrm{C}$, and $\mathrm{B}$ ), the PGA amplification factor starts to increase with the increase of concrete grade. It is indicated that PGA has more obvious amplification effect when propagating in soft rock than that of hard rock. The softer the surrounding rock, the greater the amplification effect.

In the longitudinal direction of tunnel, with the decreasing soft rock range, the PGA amplification factor gradually decreases from soft rock to hard rock. In case 4, the PGA amplification factor in soft rock section (A) is largest, which is $63.78 \%$. The main reason is that the strength and stiffness of hard rock are similar to those of support structure; the improvement of strength and stiffness for support structure is limited in 2-4 cases. When the seismic wave propagates to the interface between hard rock and support structure, the interface amplification of seismic motion is very small. Nevertheless, the strength and stiffness of soft rock are much lower than those of tunnel support structure, and the strength and stiffness of secondary lining are increased in cases 2-4, which enlarges the difference of strength and stiffness between soft rock and support structure. When seismic wave propagates to the interface between soft rock and support structure, the PGA interface amplification effect is further enhanced. The higher the strength and stiffness of support structure, the higher the PGA amplification factor. Therefore, in view of the acceleration response, increasing the concrete's strength and stiffness has limited effect on improving the aseismic property of soft tunnel portal.

3.2. Longitudinal Strain. Figure 19 plots the relationship between longitudinal strain peak of the tunnel vault and the monitoring sections. In hard rock section (i.e., sections $\mathrm{E}$ to D), the longitudinal strain peak basically has no change, while it increases gradually in the junction of soft and hard rock (i.e., sections D, C, and B) with the increasing soft rock range, and finally reaches the maximum in soft rock part (i.e., section A). It is implied that the soft rock range could directly enlarge tunnel longitudinal strain; the larger the range of soft rock in the model, the larger the longitudinal strain.

Table 4 lists the decrease rate of longitudinal strain of cases 2-4 relative to case 1 . In general, with the improvement of support structure's strength and stiffness, the longitudinal strain peak of support structure continues to decrease. In soft rock (i.e., section A), when the concrete grade is $\mathrm{C} 40$, the decrease rate of case 2 , case 3 , and case 4 is $9.97 \%, 16.98 \%$, and $21.37 \%$, respectively, and the obvious restrictive effect on longitudinal strain is observed in soft rock (i.e., section $\mathrm{A}$ ) and soft and hard rock junction (i.e., sections $B, C$, and $D$ ). While the 


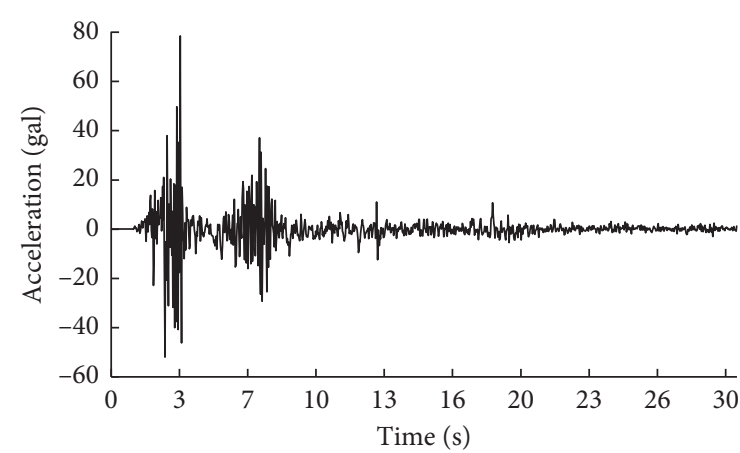

(a)

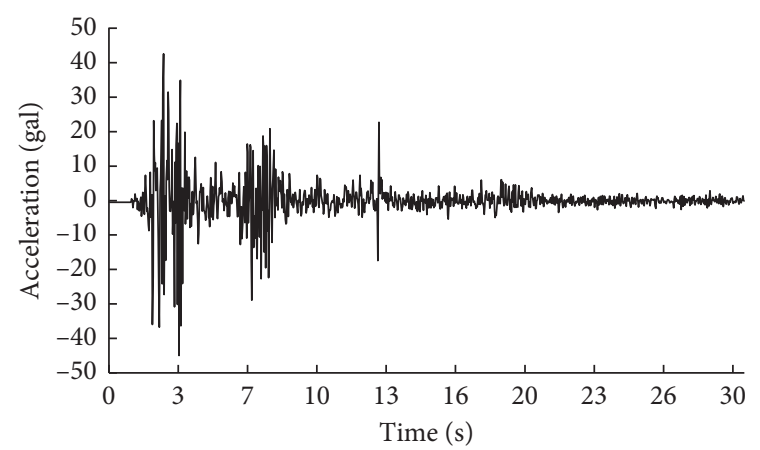

(b)

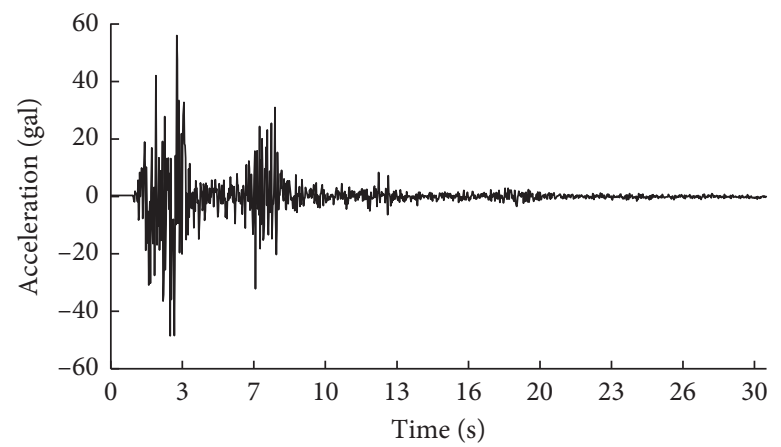

(c)

Figure 14: Input earthquake motion. (a) East-west. (b) South-north. (c) Vertical.

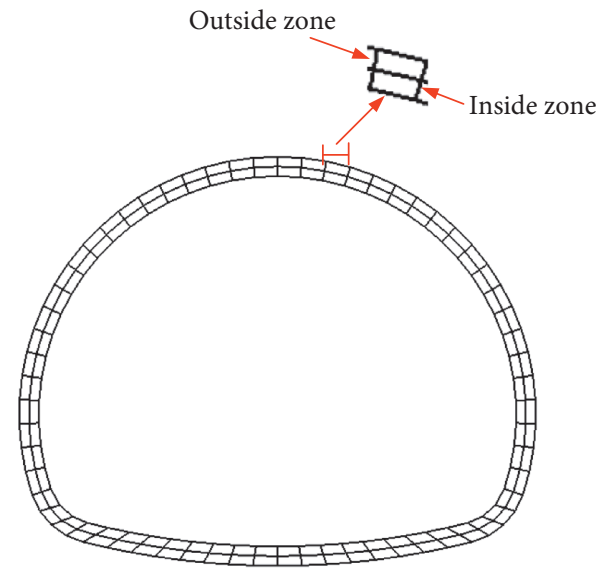

FIGURE 15: Lining models.

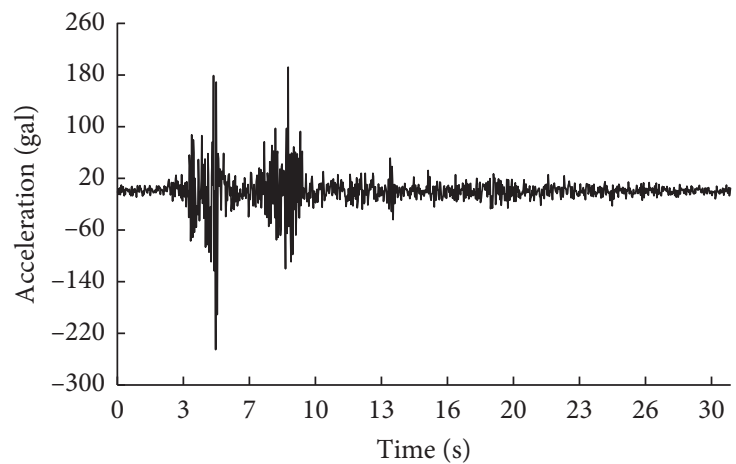

Figure 16: Acceleration time history of tunnel vault. 


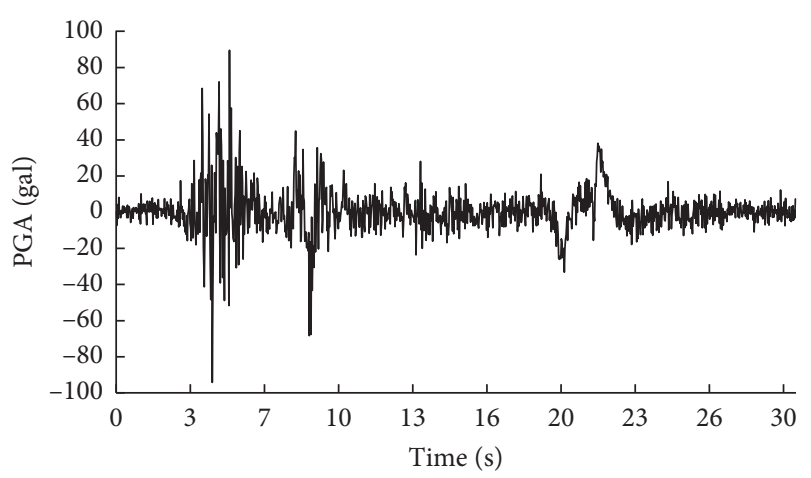

Figure 17: Acceleration time history of box bottom.

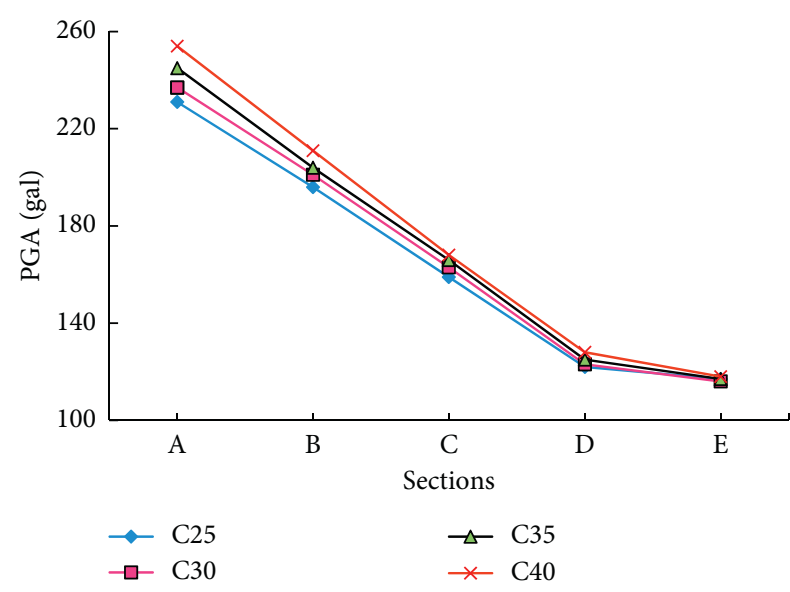

FIgURE 18: Peak ground acceleration.

TABle 3: PGA amplification factor.

\begin{tabular}{lcccc}
\hline Section & Case 1 (\%) & Case 2 $(\%)$ & Case 3 $(\%)$ & Case 4 (\%) \\
\hline A & 60.17 & 61.18 & 62.45 & 63.78 \\
B & 53.06 & 54.23 & 54.90 & 56.40 \\
C & 42.14 & 43.56 & 44.58 & 45.24 \\
D & 24.59 & 25.20 & 26.40 & 28.13 \\
E & 21.37 & 20.69 & 21.37 & 22.03
\end{tabular}

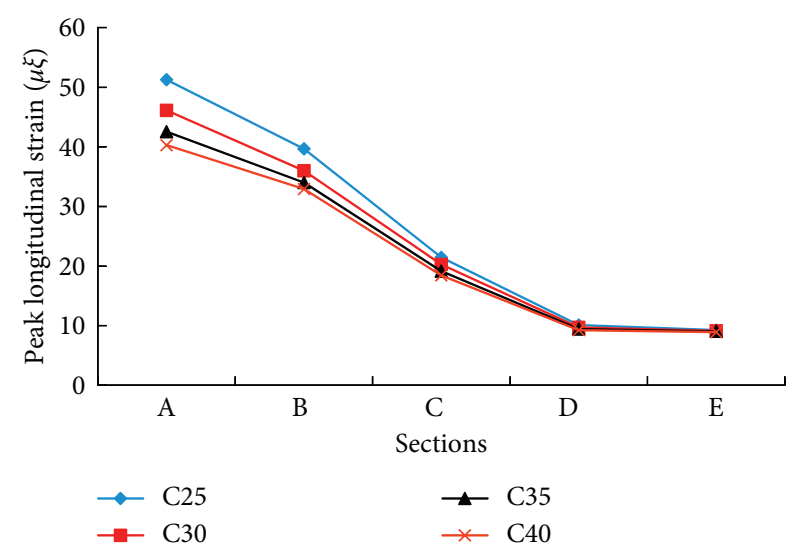

Figure 19: Peak longitudinal strain.
TABLE 4: Decrease rate of longitudinal strain.

\begin{tabular}{lccc}
\hline Section & Case 2 (\%) & Case 3 (\%) & Case 4 (\%) \\
\hline A & 9.97 & 16.98 & 21.37 \\
B & 9.30 & 14.37 & 17.04 \\
C & 5.37 & 10.69 & 14.01 \\
D & 3.57 & 6.45 & 8.34 \\
E & 1.51 & 2.49 & 3.68 \\
\hline
\end{tabular}

longitudinal strain peaks increase slightly in hard rock section (i.e., section $\mathrm{E}$ ), the maximum decrease rate of section $\mathrm{E}$ is only $3.68 \%$. The reason for this result is that the structure in hard rock is less affected by forced displacement and the seismic inertia force than soft rock, so that it suffers the weaker seismic damage during earthquake. The effect of increasing the concrete grade of support structure on reducing the longitudinal strain peak of tunnel structure in hard rock section is limited. With the increasing soft rock range of model crosssection, the decrease rate of longitudinal strain peak in soft and hard rock junction (i.e., section D, C, and B) continues to grow, and it increases from $8.34 \%$ to $17.04 \%$ in case 4 . In soft rock section, the decrease rate of longitudinal strain peak continues to the maximum, and with the $21.37 \%$ in case 4 . With concrete grade of structure continuing to improve from $\mathrm{C} 25$ to $\mathrm{C} 40$, its effect on limiting the longitudinal strain peak of tunnel structure is also strengthened.

3.3. Contact Stress. Figure 20 plots the contact stress peak of tunnel vault during the seismic loading. There are few changes of contact stress peak in hard rock section (i.e., sections E-D), while it increases rapidly at the soft and hard rock junction (i.e., sections $\mathrm{D}, \mathrm{C}$, and $\mathrm{B}$ ) with the increasing soft rock range in model cross-section.

Table 5 lists the growth rate of contact stress peak, that is, the percentage increase of contact stress in cases 2-4 relative to case 1 . With the improvement of the concrete grade of support structure, the contact stress peak continues to increase. In section A, the growth rate of contact stress peak reaches the maximum, and that is $41.69 \%$ in case 4 . In soft and hard rock junction (i.e., sections $\mathrm{B}, \mathrm{C}$, and $\mathrm{D}$ ), the growth rate of contact decreases as soft rock range reduces. However, the growth rates of hard rock section (i.e., sections E-D) are smaller than those of other sections, which is only $9.09 \%$ at section $\mathrm{E}$ in case 4 . It is implied that the seismic response of hard rock tunnel is weaker than that of soft rock, and the improvement of concrete grade for support structure has little effect on limiting the stress release of the surrounding rock. With the increase of soft rock range in model cross-section, the growth rate of contact stress peak in the soft and rock junction (D, C, and $\mathrm{B})$ continues to increase, and it increases from $20.43 \%$ to $36.68 \%$ in case 4 . In soft rock section, the growth rate of radical stress peak reaches the maximum, which is $41.69 \%$ in case 4 . The main reason is that, with the increase of soft rock range, the seismic response of support structure gradually strengthens, and the effect on limiting the release of contact stress 


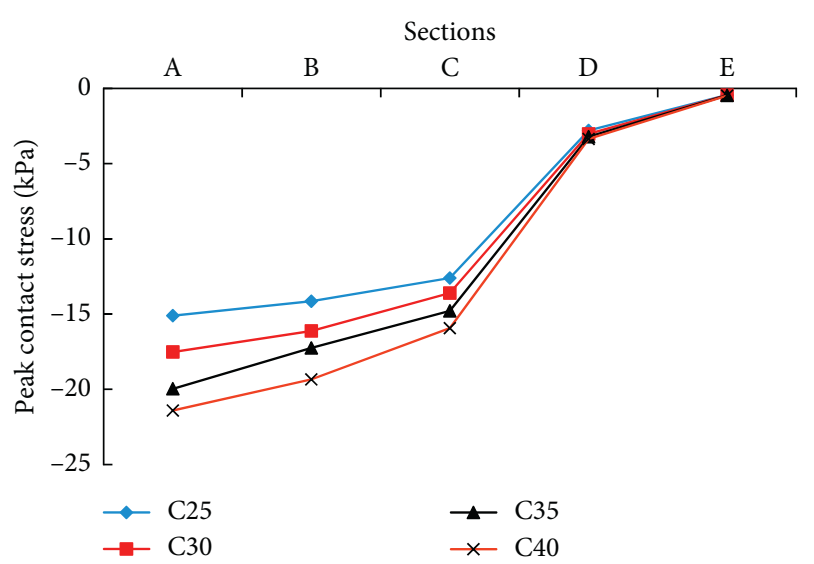

Figure 20: Contact stress peak.

TABLE 5: Growth rate of contact stress peak.

\begin{tabular}{lccc}
\hline Section & Case 2 $(\%)$ & Case 3 $(\%)$ & Case 4 $(\%)$ \\
\hline A & 15.95 & 32.16 & 41.69 \\
B & 13.92 & 21.98 & 36.68 \\
C & 7.93 & 17.29 & 26.41 \\
D & 8.60 & 15.05 & 20.43 \\
E & 2.27 & 4.55 & 9.09 \\
\hline
\end{tabular}

gradually reduces when the strength and stiffness continue to improve under cases 2-4.

3.4. Safety Factor Response. In this paper, the minimum of safety factor is used to detect the safety of tunnel structure during earthquake. Compared with other parts, the tunnel vault is the most seriously damaged part in the earthquake. Therefore, we select the minimum safety factor of the vault for the following analysis. The time history of safety factor of tunnel (take the vault of section $\mathrm{C}$ in case 3 as an example) is calculated in Figure 21.

Figure 22 plots the curve of minimum value safety factors with monitoring sections during the dynamic loading process. The minimum safety factor of hard rock section (i.e., section E) is the largest. From sections D to B, it gradually reduces with the increasing of soft rock range and finally reaches the minimum value in section $\mathrm{A}$. The larger the soft rock range, the worse the structural safety. It can be concluded from the above analysis that tunnel portal in soft rock is more dangerous than that in hard rock during earthquake.

Table 6 gives the growth rates of safety factor under cases $2-4$ relative to the case 1 . The seismic response of hard rock tunnel is weaker than that of soft rock, and seismic inertia force and forced displacement of support structure have little change with the improvement of concrete grade of secondary lining. Therefore, the minimum safety factor increases rapidly in section $\mathrm{E}$, with the growth rate of $90.16 \%$ under case 4 . With the increasing soft rock range, the seismic response of tunnel structure in soft and hard rock junction gradually is enhanced. As the concrete grade of lining increases, the seismic inertia force of structure increases

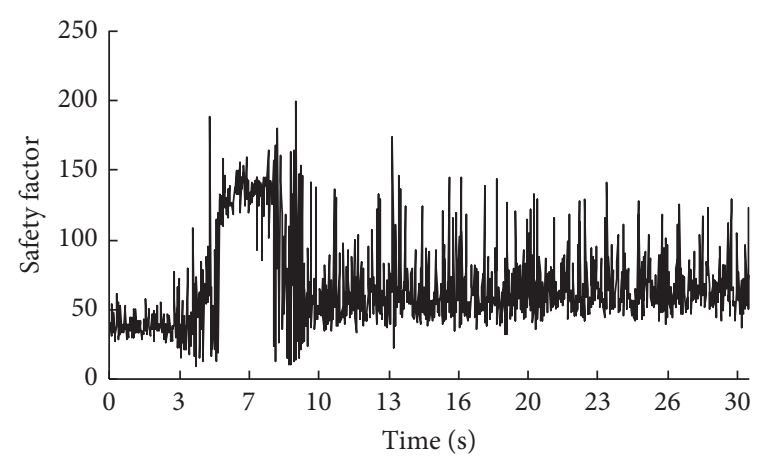

FIGURE 21: Safety factor time history.

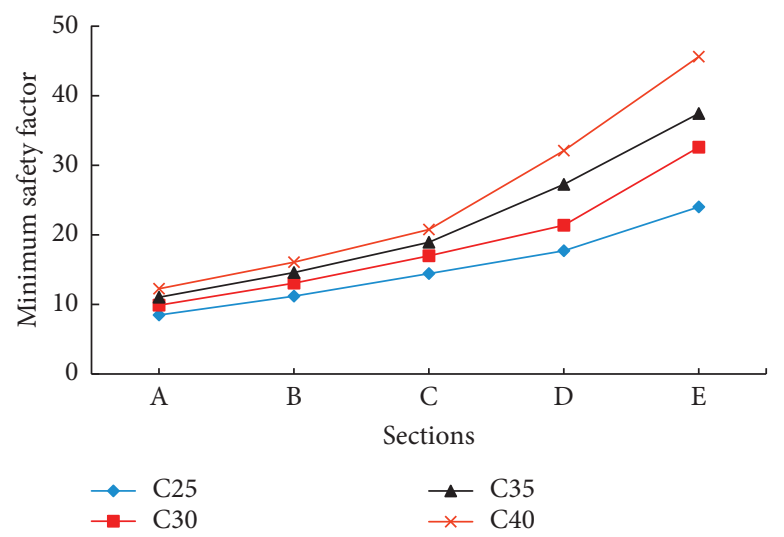

FIgURe 22: Minimum safety factor.

TABLE 6: Growth of safety factor.

\begin{tabular}{lccc}
\hline Section & Case 2 $(\%)$ & Case 3 $(\%)$ & Case 4 (\%) \\
\hline A & 16.69 & 30.30 & 44.73 \\
B & 17.03 & 30.47 & 40.50 \\
C & 17.82 & 31.21 & 43.97 \\
D & 20.72 & 65.22 & 81.31 \\
E & 31.76 & 56.11 & 90.16 \\
\hline
\end{tabular}

rapidly, and the growth rate of PAG for section A in case 4 reaches the maximum of $9.96 \%$. Though the longitudinal strain of support structure decreases, the contact stress between the structure and surrounding rock increases continuously. The growth rate of contact stress for soft rock section (A) under case 4 reaches the maximum, which is $41.69 \%$. Therefore, the growth percentage of structural minimum safety factor in soft rock section is much lower than that of hard rock, and it increases by $44.73 \%$ for section A under case 4.

\section{Discussion and Conclusions}

In view of the serious earthquake damage of soft tunnel portal section, the seismic performance of lining strengthening method for tunnel structure is studied by conducting the large-scale model test. Firstly, the shaking table test considering the test cases, the modified input motions, the boundary condition, and monitoring equipment are 
established to simulate the seismic response of the soft tunnel portal section. Then, the lining strengthening method of increasing concrete grade is applied to the tunnel structure to study the aseismic performance of the tunnel portal at the junction of soft and hard rock, and the seismic effects of the tunnel with different concrete grades are compared and analyzed. Furthermore, we evaluate the effectiveness of lining strengthening method of the soft rock portal in strong earthquakes, followed by some scientific suggestions. Although the type of the input motion, the angel of the soft-hard rock interface, and the tunnel shape are not considered in this paper, these factors will not directly affect the isolation performance of the sponge rubber buffer layer at the junction of soft and hard rock of the tunnel except for introducing irrelevant variables. Therefore, some key findings can be drawn:

(1) The proportion of soft rock to total surrounding rock is the key factor affecting the seismic response of soft rock tunnel portal section. The larger the proportion of soft rock in the surrounding rock, the more vulnerable the structure to earthquake damage.

(2) After employing the structure strengthening method in the soft rock portal section, the seismic inertia force and forced displacement of hard rock change a little, and the minimum safety factor of structure increases by $90.16 \%$ at most, while the structural minimum safety factor of soft rock only increases by $44.73 \%$ at most. The seismic performance of the lining strengthening in hard rock portal is better than that of soft rock portal.

(3) The stiffness and the strength of linings are larger than those of the surrounding rock, and the seismic performance of the soft portal section could be hardly improved only by the lining strengthening method. It is suggested to adopt both the structure strengthening and isolation method in the seismic design of soft portal section.

\section{Data Availability}

The data used to support the findings of this study are included within the article.

\section{Conflicts of Interest}

The authors declare that there are no conflicts of interest regarding the publication of this paper.

\section{References}

[1] C. H. Dowding and A. Rozan, "Damage to rock tunnels from earthquake shaking," Journal of the Geotechnical Engineering Division, vol. 104, no. 2, pp. 175-191, 1978.

[2] G. N. Owen and R. E. Scholl, Earthquake Engineering of Large Underground Structures, Federal Highway Administration, Washington, D. C, USA, 1981.

[3] K. Konagai, S. Takatsu, T. Kanai, T. Fujita, T. Ikeda, and J. Johansson, "Kizawa tunnel cracked on 23 October 2004 Mid-Niigata earthquake: an example of earthquake-induced damage to tunnels in active-folding zones," Soil Dynamics and Earthquake Engineering, vol. 29, no. 2, pp. 394-403, 2009.

[4] T. Li, "Damage to mountain tunnels related to the Wenchuan earthquake and some suggestions for aseismic tunnel construction," Bulletin of Engineering Geology and the Environment, vol. 71, no. 2, pp. 297-308, 2012.

[5] C.-C. Lu and J.-H. Hwang, "Nonlinear collapse simulation of Daikai Subway in the 1995 Kobe earthquake: necessity of dynamic analysis for a shallow tunnel," Tunnelling and Underground Space Technology, vol. 87, pp. 78-90, 2019.

[6] W. L. Wang, T. T. Wang, J. J. Su, C. H. Lin, C. R. Seng, and T. H. Huang, "Assessment of damage in mountain tunnels due to the Taiwan Chi-Chi Earthquake," Tunnelling and Underground Space Technology, vol. 16, no. 3, pp. 133-150, 2001.

[7] G. Tsinidis, F. De Silva, I. Anastasopoulos et al., "Seismic behaviour of tunnels: from experiments to analysis," Tunnelling and Underground Space Technology, vol. 99, p. 103334, 2020.

[8] Y. Shen, B. Gao, X. Yang, and S. Tao, "Seismic damage mechanism and dynamic deformation characteristic analysis of mountain tunnel after Wenchuan earthquake," Engineering Geology, vol. 180, pp. 85-98, 2014.

[9] G. Cui, M. Wang, G. Lin, W. Zhang, and W. Wang, "Study of the earthquake damage mechanism and aseismatic countermeasure of a highway tunnel portal section in the Wenchuan seismic disaster area," Xiandai Suidao Jishu, vol. 48, no. 6, pp. 6-10, 2011.

[10] M. J. Avanaki, "Response modification factors for seismic design of steel fiber reinforced concrete segmental tunnels," Construction and Building Materials, vol. 211, pp. 1042-1049, 2019.

[11] S. Shimamura, H. Kasai, and H. Masakazu, "Seismic isolation effect for a tunnel with a soft isolation layer," Structural Engineering Earthquake Engineering, vol. 16, no. 2, pp. 143s-154s, 1999.

[12] T. Suzuki, I. Takatori, I. Okada, and R. Hagiwara, "New seismic isolation design for urban tunnels in consideration of slip and its application to an actual shield-driven tunnel," in Proceedings of the AITES-ITA Downunder 2002: 28th ITA General Assembly and World Tunnel Congress, pp. 2-8, Sydney, Australia, March 2002.

[13] C. L. Xin, Z. Z. Wang, and J. Yu, "The evaluation on shock absorption performance of buffer layer around the cross section of tunnel lining," Soil Dynamics and Earthquake Engineering, vol. 131, p. 106032, 2020.

[14] Q. Chen, X. Shan, and H. Zeng, "Analysis of influences of foam concrete buffer layer on seismic responses of tunnels," Journal of Fuzhou University. Natural Science Edition, vol. 41, no. 4, pp. 687-693, 2013.

[15] Y. S. Shen, Z. Z. Wang, J. Yu, X. Zhang, and B. Gao, “Shaking table test on flexible joints of mountain tunnels passing through normal fault," Tunnelling and Underground Space Technology, vol. 98, p. 103299, 2020.

[16] B. Chiaia, A. P. Fantilli, and P. Vallini, "Combining fiberreinforced concrete with traditional reinforcement in tunnel linings," Engineering Structures, vol. 31, no. 7, pp. 1600-1606, 2009.

[17] M. S. Abdollahi, M. Najafi, A. Y. Bafghi, and M. F. Marji, "A 3D numerical model to determine suitable reinforcement strategies for passing TBM through a fault zone, a case study: safaroud water transmission tunnel, Iran," Tunnelling and Underground Space Technology, vol. 88, pp. 186-199, 2019. 
[18] R. Das and T. N. Singh, "Effect of rock bolt support mechanism on tunnel deformation in jointed rockmass: a numerical approach," Underground Space, 2020, In press.

[19] C. L. Xin, Z. Z. Wang, J. M. Zhou, and B. Gao, "Shaking table tests on seismic behavior of polypropylene fiber reinforced concrete tunnel lining," Tunnelling and Underground Space Technology, vol. 88, pp. 1-15, 2019.

[20] L. M. Massone and F. Nazar, "Analytical and experimental evaluation of the use of fibers as partial reinforcement in shotcrete for tunnels in Chile," Tunnelling and Underground Space Technology, vol. 77, pp. 13-25, 2018.

[21] MOHURD, Code for Design of Concrete Structures, China Construction Industry Press, Beijing, China, 2011.

[22] Ministry of Transport of the Peoples's Republic of China, Code for Design of Road Tunnel, China Communication Publishing \& Media Management Co., Ltd, Beijing, China, 2004.

[23] Railway \& Train Standard of the People's Republic of China, Code for Design of Railway Tunnel: TB 10003-2016, China Railway Publishing House, Beijing, China, 2017. 